\title{
Environmental change over 28 years in a subtropical salt marsh: optimal classification and pictures from the exposition. \\ --Manuscript Draft--
}

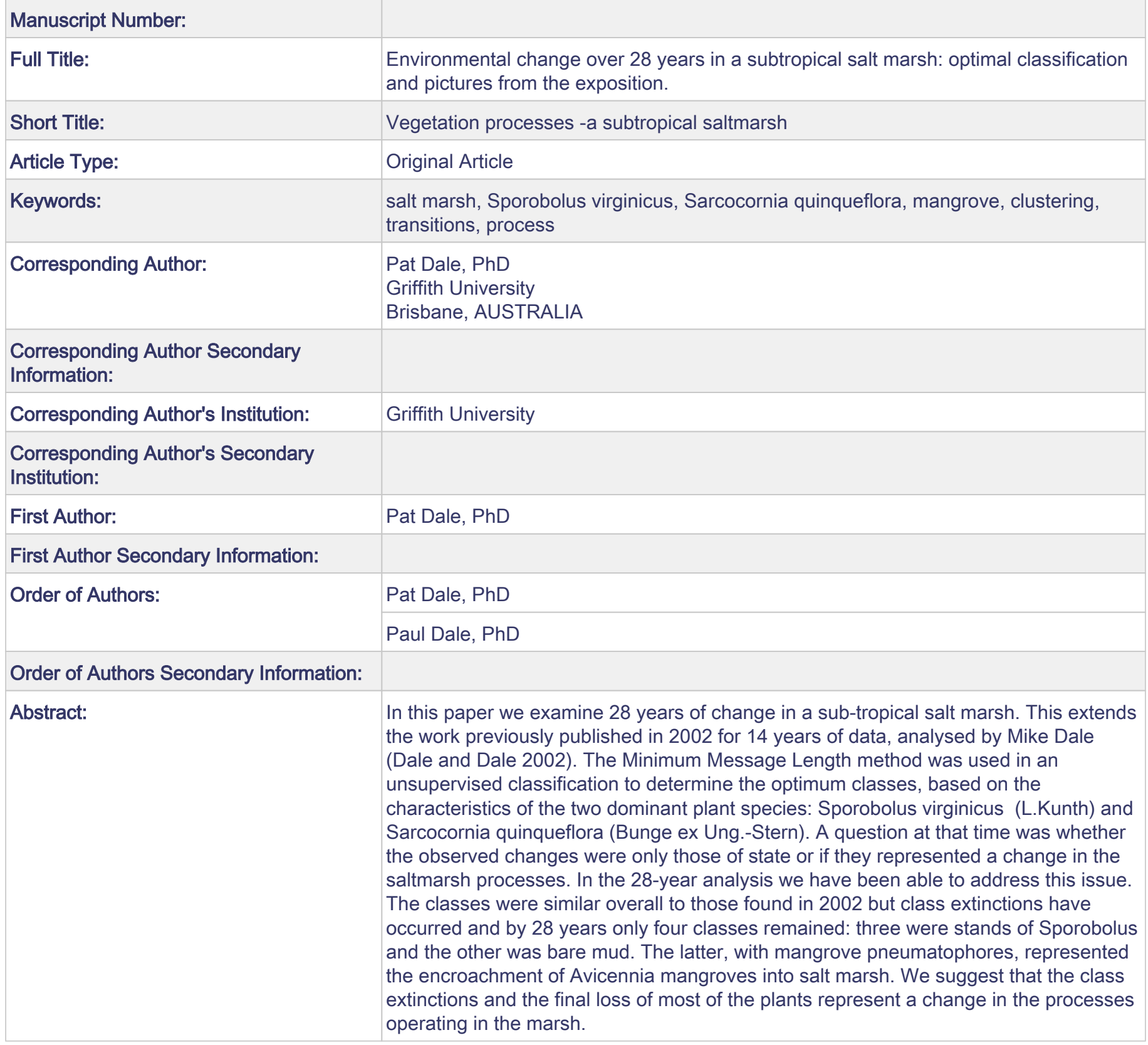




\title{
Environmental change over 28 years in a subtropical salt marsh: optimal classification and pictures from the exposition.
}

\author{
Paul Dale ${ }^{1}$ and Pat Dale 2,3 \\ 1E-mail: ppzgs1@gmail.com
}

2 Environmental Futures Research Institute, Griffith School of Environment, Griffith University, Nathan Campus, Kessels Road, Nathan Australia, 4111. E-mail: p.dale@griffith.edu.au

3 Corresponding author

A paper dedicated to the memory of Professor Michael Bodley Dale 1936 -2014

Running title: Vegetation processes in a subtropical saltmarsh over 28 years.

No more things should be presumed to exist than are absolutely necessary.

- Mark Haddon, The Curious Incident of the Dog in the Night-Time

Keywords: salt marsh, Sporobolus virginicus, Sarcocornia quinqueflora, mangrove, clustering, transitions, process.

\begin{abstract}
In this paper we examine 28 years of change in a sub-tropical salt marsh. This extends the work previously published in 2002 for 14 years of data, analysed by Mike Dale (Dale and Dale 2002). The Minimum Message Length method was used in an unsupervised classification to determine the optimum classes, based on the characteristics of the two dominant plant species: Sporobolus virginicus (L.Kunth) and Sarcocornia quinqueflora (Bunge ex Ung.Stern). A question at that time was whether the observed changes were only those of state or if they represented a change in the saltmarsh processes. In the 28-year analysis we have been able to address this issue. The classes were similar overall to those found in 2002 but class extinctions have occurred and by 28 years only four classes remained: three were stands of Sporobolus and the other was bare mud. The latter, with mangrove pneumatophores, represented the encroachment of Avicennia mangroves into salt marsh. We suggest that the class extinctions and the final loss of most of the plants represent a change in the processes operating in the marsh.
\end{abstract}

Abbreviation: MML - Minimum Message Length

\section{Introduction}

This paper extends the analysis by Dale and Dale (2002) of a 14-year data set that explored the impacts of habitat modification for mosquito control on a south-east Queensland sub-tropical salt marsh using a Minimum Message Length (MML) approach. Dale (2002) found no significant effect of the 
modification (runnelling). This conclusion has been supported by other research indicating that runnelling has had little impact on the salt marsh (Dale et al. 2002; Dale 2008; Dale \& Knight 2012) so we have not further explored differences between the treatment and control here. We continue the research that Mike Dale was engaged in at the time of his death, when he was analysing 28 years of data from the same study area, again using the Minimal Message Length (MML) approach. We have applied the same methodology and research process here (for details of the process see Fig. 1 in Dale and Dale, 2002).

Dale and Dale (2002) noted that changes from class to class could represent a single process within which some sites (samples) shift between states (classes) or it might be that the process itself changes, resulting in new states or the extinction of older ones. The analysis of 14 years of data, although providing clear evidence of state changes, did not provide evidence of a process change. With a further 14 years of data we can start to address this issue.

The original method reported in Dale and Dale (2002) modelled the salt marsh vegetation using the MML principle to cluster the samples (see Boulton and Wallace 1970; Wallace, 2005; Dowe, 2011). As Mike Dale wrote in the 2002 paper (p 21):

“MML can be regarded as implementing a form of Occam's Razor, in which simplicity is balanced against complexity in explaining phenomena. The former is represented by the message length needed to encode the cluster descriptions, the latter by the likelihood of the data conditional on the model."

The information length in MML is measured in 'nits'. These are 'natural bits' and are explained in Wallace (2005). Other benefits of the approach are that it is statistically invariant (i.e., transforming the co-ordinates does not affect the answer (Visser et al. 2012) and is stable in the presence of noise (which is common in ecological data). It is also useful where model uncertainty is important (Dale and Dale 2004). These benefits make it an appropriate tool for the current ecological research. For a recent review of MML modeling see Kasarapu and Allison (2015).

The aim here is to repeat the MML analysis using 28 years of data, leading to construction of a process model illustrating changes of state and potentially of process.

\section{Data and methods}

\section{Study area and data}

The study area is a 0.5 ha intertidal salt marsh on Coomera Island (S27 ${ }^{\circ}$ $51^{\prime}, \mathrm{E} 153^{\circ} 33^{\prime}$ ), at the northern end of the Gold Coast, south-east Queensland, Australia. Vegetation is relatively simple and composed of Marine Couch (Sporobolus virginicus (L. Kunth)) and Samphire (Sarcocornia quinqueflora (Bunge ex Ung.-Stern)). There is Grey Mangrove (Avicennia marina (Forsk)) 
along the tidal inlet that floods the marsh. Generally mangroves are encroaching onto saltmarsh in Eastern Australia and specifically in south-east Queensland and this is related to rainfall and land use changes (EslamiAndergoli et al. 2009, 2010). In the study area early research indicated that the encroachment was not related to the modification (Jones et al. 2004). The area has semidiurnal tides and a tidal range of around $2 \mathrm{~m}$. The marsh floods each month and more often on tides that are at least $2.45 \mathrm{~m}$ Australian Height Datum (around $0.28 \mathrm{~m}$ above Mean High Water Spring tides).

Data were collected every three months for 20 years between November 1984 and November 2005, with additional data collected during November 2008 and 2013. Plant data were collected in $3010 \times 10 \mathrm{~cm}$ quadrats recording size and density of the two species (Sporobolus, a grass and Sarcocornia, a succulent). These were used for the clustering process. As well, data were recorded each time for soil water content, soil water salinity and $\mathrm{pH}$, water table depth and salinity. These were not used in the clustering. After 8 years crab holes became apparent in the quadrats and after 9 years mangrove (Avicennia) pneumatophores appeared and so the data collection was modified to include these. For more detail on method please refer to Dale et al. (1993).

\section{Clustering}

The MML clustering used a freely available program (Vanilla Snob, authored by Chris Wallace, at: http://www.datamining.monash.edu.au/software/snob/). To check for comparability with the earlier analysis we analysed the 14-year data set with the method as downloaded. There was no apparent difference between the resulting classes and those from the 2002 analysis. The 28 years of data were then analysed in the same way using the same four attributes - the size and density of the two plant species. The clusters with the minimal message length were selected for further processing.

\section{Processing of the cluster results}

The processing of the cluster results followed a similar pattern to that in Dale and Dale (2002). The clustering determined the 'best' classes. The classes were described and tabulated in terms of their plant characteristics. The presence of classes were plotted by month for all the data. Next a transition matrix was calculated from the results. That is, for each sample site the transitions between classes over the 28 years were enumerated. This was used to construct the process model 'picture' as was done in the 2002 paper, showing symbolically how each class changed over subsequent observations. It indicated relatively stable classes and those which changed from class to class over time. We used a cut off of $10 \%$ change from one class to another to show strong change and a $5 \%$ cut off for less frequent changes. Classes remaining in the same class from time to time were also noted.

\section{Class associations with other attributes}


We further investigated associations between the classes from the MML used an ANOVA with classes as the treatment. Where there were significant ANOVA results we did an extended t-test and means comparison to identify specific class relationships.

\section{Results}

Clusters

The MML procedure indicated that a 13-class cluster had the minimal message length. The 1- class length (all the data ignoring any pattern) was 73228.7 nits, whereas the 13 -class length was only 42250.6 nits. The redundancy or structure captured is the difference between these numbers, in this case 30978.1. The greater the size of this difference the more likely it is that the clusters did not occur by chance. This represents an odds ratio in favour of the 13 cluster solution, compared to one cluster solution of $e^{30978.1}: 1$ or $\sim 4 \mathrm{x} 10^{13453:} 1$ which is a VERY large number. We therefore accept first, that clusters exist in these data and second, that 13 is a reasonable estimate of the number of such clusters.

\section{Vegetation classes}

Table 1 shows the vegetation classes, number of samples in each class and the plant characteristics. The classes are similar to those reported in Dale and Dale (2002) with Sporobolus and Sarcocornia alone or in combination distinguished by their size, density and species combinations.

Insert Table 1

\section{Distribution over time (28 years of data)}

Fig. 1 illustrates the distribution of classes over time (by months from the start in 3-month steps). It shows that a few classes persisted throughout the 28 years whereas others died out in the late 1990s (Classes 3, 4 and 5), and others that were not there at the start came into existence later e.g., Classes 10 and 13 in 1990 (very sparse Sporobolus and mud); Class 7 in 1987 (tall sparse Sporobolus) and class 5 (tall sparse Sporobolus and dense Sarcocornia in 1986.

Insert Fig. 1

\section{Transition matrix}

The transition matrix is shown in Table 2. The first column is the starting class for any transition and the rows indicate the number of changes from the starting class to other classes (top row) or how many stayed the same (on the 
diagonal). The transition matrix will not be discussed in detail here as it was used to construct the process model and transitions are more clearly indicated in the model (Fig. 2).

\section{Insert Table 2}

\section{The process model}

Fig. 2 shows the process model illustrating the plant descriptions for each class with the processes identified from the transition matrix (Table 2). The model shows pathways of change from class to class, indicating, for example, reduction in plant size and density or recovery. This can be illustrated by the transitions between the Sporobolus classes on the left side of Fig. 2. The changes from Classes 1 to 2 to 7 indicate reducing plant size and density. Changes from Classes 10 to 7 to 2 suggest recovery.

Some classes are relatively stable. The three most stable are classes 2,12 and 13. Class 2 persists for the whole time period (with some Class 7 and Class 1 ). Classes 12 and 13 are large classes and represent increase in bare mud generally and the ultimate demise of the Sarcocornia component of the marsh (the last record of Sarcocornia in the field data was in 2008 when it was present in only three samples).

\section{Insert Fig. 2}

In more detail the process model shows two main pathways of change. The simplest is on the left representing Sporobolus classes whereby change is evidenced in the size and density of the plants. Between classes 1 and 2 there is a strong connections in both directions; other transitions appear to be asymmetrical. For example the transition from Class 2 to Class 7 is relatively weak (6\% of transitions from Class 2), with Sporobolus declining in size and density, whereas the reverse is a stronger transition $(16 \%$ of transitions from Class 7 to Class 2).

On the right hand side of Fig. 2 the transitions are more complicated with multiple links. The main link to the pure Sporobolus classes on the left are by a transition via Class 3 (or a by a very complex set of changes at the lower end of the figure). However Class 3 also has strong links to Classes 4 and 6, each with increasing amounts of Sarcocornia. These classes link directly or indirectly to Class 9 with reduced plant size and density. Class 9 begins the sequence to 12 to 11 to 13, which latter represents bare mud and the loss of Sarcocornia. While recovery appears possible the reverse transitions are mainly weak ones.

Fig. 3 illustrates the sequence of classes for two samples: one, Fig. 3A, illustrates the Sporobolus sequence; the other, Fig. 3B, shows an example of the Sarcocornia sequence that starts with the 4-5-6 circulation and finishes with the 9-13 extinction of the species. 
Insert Fig. 3

The sequences are generally consistent with the process model in Fig. 2 with very minor difference related to the $5 \%$ cut off for transitions that resulted in rare changes not being included in the model. For example, in Fig. 3A Class 3 transitioned strongly to Class 2 once (as in the model) but, in the specific sequence illustrated, it also transitioned back from Class 2 to Class 3 (in 1992). This only occurred in $2 \%$ of the transitions from Class 2 . In Fig. 3B the transitions were more complex and Class 6 shows two direct transitions to Class 4 not in the model (this occurred in only $3 \%$ of transitions from Class $6(n=6)$ ). Similarly Class 12 transitioned to Class 5 (in 1990) but this only occurred once for the whole data matrix. Class 6 transitioned directly to Class 12 in 1996 (2\% of transitions from class 6).

\section{Class associations with other attributes}

There are relationships between some classes and the attributes that were not used in the classification (soil water content, soil salinity and $\mathrm{pH}$; water table salinity; and pneumatophores and crab holes). This is shown in Table 3 and discussed below.

\section{Insert Table 3}

Soil water content and salinity. Classes with Sporobolus and without Sarcocornia (Classes 1, 2, 7 and 10, ranging from tall dense to shorter less dense stands) were all associated with significantly higher soil water content and, except for Class 2, had significantly lower soil salinity. Class 7 (tall, very sparse Sporobolus) also had significantly lower water table salinity. Although not significant, the Sporobolus classes tended to be further from the tidal source ( $>90 \mathrm{~m}$ except for Class 10).

Classes associated with significantly lower soil water content (Classes 5, 8 and 11) were mainly of large - medium dense Sarcocornia (with some sparse Sporobolus in classes 5 and 8). Classes 5 and 8 (and also class 4) were associated with high water table salinity. Classes 11 and 12 with only Sarcocornia were associated with lower soil water content and lower water table salinity (but not significantly so for Class 12 ).

In the process model they are connected with a strong connection from class 11 (which remained the same for only 7\% of transitions) to Class 12 and a high percentage of samples in Class 12 remained in that class (81\%).

Pneumatophores and crab holes. Classes 10 and 13 are characterised by mangrove pneumatophores and crab holes that appeared 8-9 years after the monitoring began. Class 10 had high soil water content and a significantly higher number of crab holes; Class 13 was bare mud and with significantly higher numbers both of pneumatophores and crab holes (and lower water table salinity). Linked to Class 13 were Classes $7-12$, also with pneumatophores, and which were part of the 
process of loss of vegetation cover from relatively tall sparse Sporobolus to shorter Sporobolus (Class 10) to bare mud (Class 13) with some oscillation between the Sarcocornia classes (11 and 12).

\section{Discussion}

The classes identified using 28 years of data are broadly similar to those identified in the 14 years analysis of Dale and Dale (2002). The tall dense Sporobolus is a distinct class in both, but with variation in terms of size and density in the 28-year analysis. The Sarcocornia and Sarcocornia/ Sporobulus classes are also outputs of both analyses with similar associations between classes and variables not used in the classification process. For example the tall dense Sporobolus class (Class 1 in both the 14-year and 28-year analyses) was associated with a soil water content of $61 \mathrm{~g} / \mathrm{g}$ (relatively wet); at the other extreme bare ground (mud) (Class 11 in the 14 year analysis; Class 13 here) was associated with being closer to the tidal source ( $69 \mathrm{~m}$ and $78 \mathrm{~m}$ respectively). That there was a three-year gap and then a five-year gap in the data after the end of the 20 year data collection in 2005 does not seem to have affected the results of the MML, as no new classes emerged at those later periods.

The 2002 paper noted that the results of the analysis did not allow distinction between changes of state (within a single process) or a change in the process itself. We suggest that the results from the additional years of data provide compelling evidence to indicate not only changes in state but also a change in process. The extinction of some classes (not evident in the 14 year analysis) might reflect a change in the underlying drivers of the system and indicate a process change. For example, Class 5 - the very 'unstable' class, became extinct in 1998 (see above and Fig. 1). Other extinctions included Class 4 in 1996; Class 3 in 1999; Classes 6, 8 and 9 in 2001. These were all part of the connected Sarcocornia Classes and it seems that once in that part of the process the samples were doomed to become bare mud. At the end of the period, after 28 years, there were only four remaining classes: Class 1, Class 2, Class 7 (all Sporobolus) and Class 13 (bare mud). Checking the field data shows that in the final year only four samples had any vegetation and this consisted of Sporobolus. The local extinction of some classes indicates that a tipping point may have been passed and this strongly supports a change in process. Using the same data in another context Eslami-Andergoli et al. (2015) showed that some indicators of tipping points were manifest at the Coomera site (e.g., increasing variance, increasing skewness).

The drivers underlying the process of change are not indicated by our analysis but the associations with other attributes suggests that water and its salinity are important (in the soil and water table). This in turn might indicate that some aspect of climate change related to rainfall or sea level is leading to significant alteration in marsh processes in this area. There is evidence that sea level in the general area is rising at a rate of around $3 \mathrm{~mm} /$ year (National Tidal Centre 2011), but what is not certain is how far marsh accretion will adjust for this. Rainfall can be very variable and was shown to be a driver of mangrove encroachment into salt marsh to the north of the study area (Eslami-Andergoli et 
al. 2009). Analysis of rainfall and sea level is beyond the scope of this paper but worthy of further research.

\section{Conclusion}

We have shown that the MML method has simplified the salt marsh system to provide a clear and simple exposition of the states or classes that exist or have existed within the salt marsh and an interpretable process model. The issue of change in state within a process or a change in the process itself has been addressed and we conclude that there is evidence that the underlying process has changed and that this may be related to local climate changes including rainfall and sea level. This would benefit from further research in the future.

Finally, as Mike Dale wrote in his last paper (Dale 2013), we include a quote from Isaac Newton:

"Truth is ever to be found in the simplicity, and not in the multiplicity and confusion of things"

Acknowledgements. We thank the many students who have helped to collect the field data. Financial support has been received from time to time from Local Governments in south-east Queensland (especially from the Gold Coast City) and from the Mosquito and Arbovirus Research Committee and the Queensland Department of Health.

\section{References}

Boulton, D.M. and C.S. Wallace. 1970. A program for numerical classification. Comput. J. 13:63-69.

Dale, M.B. 2013. Compression and knowledge discovery in ecology. Community Ecology 14, 196-207.

Dale P.E.R. 2008. Assessing impacts of habitat modification on a subtropical salt marsh: 20 years of monitoring. Wetlands Ecology and Management 16: 77-87.

Dale, P.E.R., Dale, P.T., Hulsman, K. and B.H. Kay. 1993. Runnelling to control saltmarsh mosquitoes: long-term efficacy and environmental impacts. J. Amer. Mosq. Control Assoc. 9 (2): 174-181.

Dale, P and J. Knight. 2012. Managing mosquitoes without destroying wetlands: an eastern Australian approach. Wetlands Ecology and Management. 20 (3): 233-242.

Dale, P.E.R. and M.B.Dale. 2002. Optimal classification to describe environmental change: pictures from the exposition. Community Ecology 3 (1): 19-29. 

perturbations using a model-based approach. Ecological Modelling 156:185-199.

Dale, M.B. and P.E.R. Dale. 2004. Sources of Uncertainty in Ecological Modelling: Predicting Vegetation Types from Environmental Attributes. Community Ecology 5 (2): 203-225.

Dowe D.L. 2011. MML, hybrid Bayesian network graphical models, statistical consistency, invariance and uniqueness. In: Bandyopadhyay PS, Forster MR, (eds) Handbook of the Philosophy of Science) (HPS Vol 7). 901-982, Philosophy of Statistics. Elsevier, North Holland, Netherlands.

Eslami-Andargoli, L. Dale, P.E.R., N Sipe N. and J Chaseling. 2009. Mangrove expansion and rainfall patterns in Moreton Bay, southeast Queensland, Australia, Australia. Estuarine and Coastal Shelf Science 85: 292-298

Eslami-Andargoli, L. Dale, P.E.R., N Sipe N. and J Chaseling. 2010. Local and landscape effects on spatial patterns of mangrove forest during wetter and drier periods: Moreton Bay, Southeast Queensland, Australia. Estuarine and Coastal Shelf Science 89 (1): 53-61

Eslami-Andergoli, L Dale P, Knight JM, and H. McCallum 2015. Approaching tipping points: a focussed review of indicators and relevance to managing intertidal ecosystems. Wetlands Ecology and Management 23 (5): 791-802.

Jones, J., Dale, P.E.R., A.L. Chandica, A.L. and M. J. Breitfuss. 2004. Distribution changes of the Grey Mangrove Avicennia marina (Forsk.) using large scale aerial color infrared photographs: are the changes related to habitat modification for mosquito control? Estuarine and Coastal Shelf Science 61(1): 45-54.

National Tidal Centre, Bureau of Meteorology. 2011. The Australian Baseline Sea Level Monitoring Project, Annual Sea Level Data Summary Report, July 2010- June 2011. Australian Government, 41 pp.

Kasarapu, P. and L. Allison. 2015. Minimum message length estimation of mixtures of multivariate Gaussian and von Mises-Fisher distributions. Mach. Learn. 100: 333-378.

Visser, G., Dale, P. E. R., Dowe, D. L., Ndoen, E., Dale, M.B. and N. Sipe. 2012. A novel approach for modeling malaria incidence using complex categorical household data: the minimum message length (MML) method applied to Indonesian data. Computational Ecology and Software 2(3):140-159.

Wallace, C.S. 2005. Statistical and Inductive Inference by Minimum Message Length. Information Science and Statistics. Springer, New York, USA. 
Table 1. Vegetation classes. Mean values for the plant attributes for each class (Sp - Sporobolus; Sa - Sarcocornia)

\begin{tabular}{|c|c|c|c|c|c|c|}
\hline $\begin{array}{c}\text { Class } \\
\text { ID }\end{array}$ & Class Description & $\begin{array}{c}\# \\
\text { samples }\end{array}$ & Sp \# & $\begin{array}{l}\text { Sp } \\
\text { Height } \\
(\mathrm{mm})\end{array}$ & Sa \# & $\begin{array}{c}\text { Sa Size } \\
(\mathrm{mm})\end{array}$ \\
\hline 1 & $\begin{array}{l}\text { Extremely tall, very dense } \\
\text { Sporobolus }\end{array}$ & 215 & 182.14 & 128.77 & 0 & 0 \\
\hline 2 & $\begin{array}{l}\text { Very tall, medium dense } \\
\text { Sporobolus }\end{array}$ & 566 & 90.20 & 101.23 & 0 & 0 \\
\hline 3 & $\begin{array}{l}\text { Very tall, medium dense } \\
\text { Sporobolus; medium, sparse } \\
\text { Sarcocornia }\end{array}$ & 57 & 89.79 & 102.45 & 7.19 & 50.19 \\
\hline 4 & $\begin{array}{l}\text { Tall, medium dense Sporobolus; } \\
\text { short, medium dense } \\
\text { Sarcocornia }\end{array}$ & 88 & 85.96 & 81.73 & 33.10 & 38.57 \\
\hline 5 & $\begin{array}{l}\text { Tall, sparse Sporobolus; very } \\
\text { large, dense Sarcocornia }\end{array}$ & 33 & 38.76 & 86.26 & 60.42 & 126.19 \\
\hline 6 & $\begin{array}{l}\text { Tall, sparse Sporobolus; short, } \\
\text { medium dense Sarcocornia }\end{array}$ & 175 & 23.39 & 87.08 & 33.45 & 38.25 \\
\hline 7 & Tall, very sparse Sporobolus & 165 & 17.09 & 94.63 & 0 & 0 \\
\hline 8 & $\begin{array}{l}\text { Short. very sparse Sporobolus; } \\
\text { medium, dense Sarcocornia }\end{array}$ & 62 & 10.02 & 43.74 & 74.00 & 57.97 \\
\hline 9 & $\begin{array}{l}\text { Medium, very sparse } \\
\text { Sporobolus; short, medium } \\
\text { dense Sarcocornia }\end{array}$ & 143 & 3.71 & 60.55 & 40.09 & 39.23 \\
\hline 10 & $\begin{array}{l}\text { Medium, very sparse } \\
\text { Sporobolus }\end{array}$ & 161 & 3.28 & 71.55 & 0 & 0 \\
\hline 11 & Large, very dense Sarcocornia & 31 & 0 & 0 & 92.32 & 75.83 \\
\hline 12 & $\begin{array}{l}\text { Short, medium dense } \\
\text { Sarcocornia }\end{array}$ & 440 & 0 & 0 & 41.83 & 43.31 \\
\hline 13 & Bare mud & 324 & 0 & 0 & 0 & 0 \\
\hline
\end{tabular}


Table 2. Transition matrix

\begin{tabular}{|l|l|l|l|l|l|l|l|l|l|l|l|l|r|r|}
\hline $\begin{array}{l}\text { To -> } \\
\text { From } \\
\dot{v}\end{array}$ & 1 & 2 & 3 & 4 & 5 & 6 & 7 & 8 & 9 & 10 & 11 & 12 & 13 & TOTAL \\
\hline 1 & $\mathbf{1 2 5}$ & $\mathbf{8 5}$ & 2 & & & & 2 & & & & & & & 214 \\
\hline 2 & $\mathbf{8 1}$ & $\mathbf{4 1 6}$ & 14 & 6 & 1 & 5 & 34 & & & 1 & & 1 & 6 & 565 \\
\hline 3 & 2 & $\mathbf{1 4}$ & 18 & $\mathbf{1 5}$ & 1 & $\mathbf{7}$ & & & & & & & & 57 \\
\hline 4 & & 3 & $\mathbf{1 2}$ & $\mathbf{4 8}$ & 7 & $\mathbf{1 6}$ & & 1 & & & & 1 & & 88 \\
\hline 5 & & & 3 & $\mathbf{6}$ & 4 & $\mathbf{1 5}$ & & 1 & $\mathbf{4}$ & & & & & 33 \\
\hline 6 & & 5 & 7 & 6 & 14 & $\mathbf{9 2}$ & 7 & 11 & $\mathbf{2 6}$ & 2 & 2 & 3 & & 175 \\
\hline 7 & 1 & $\mathbf{2 6}$ & & & 1 & 2 & $\mathbf{9 8}$ & & 1 & $\mathbf{2 4}$ & & 1 & 9 & 163 \\
\hline 8 & & & & & 1 & $\mathbf{1 6}$ & & 21 & $\mathbf{2 1}$ & & 1 & 2 & & 62 \\
\hline 9 & & & & 1 & 3 & $\mathbf{1 8}$ & 1 & $\mathbf{1 9}$ & 59 & 2 & 1 & $\mathbf{3 5}$ & 4 & 143 \\
\hline 10 & & & & & & 1 & 16 & & 3 & $\mathbf{9 0}$ & 1 & & $\mathbf{5 0}$ & 161 \\
\hline 11 & & & & & & & 1 & 1 & 1 & & 2 & $\mathbf{2 4}$ & 2 & 31 \\
\hline 12 & & 3 & & & 1 & & 2 & 6 & 24 & & 22 & $\mathbf{3 5 5}$ & 27 & 440 \\
\hline 13 & & 5 & & & & & 4 & & 1 & $\mathbf{4 2}$ & 2 & 18 & $\mathbf{2 2 6}$ & 298 \\
\hline TOTAL & 209 & 557 & 56 & 82 & 33 & 172 & 165 & 60 & 140 & 161 & 31 & 440 & 324 & \\
\hline
\end{tabular}

Diagonal values are lightly shaded (i.e., the class stayed the same from one tine to the next). Relatively stable classes (where there was no change $>50 \%$ of the time - bold (median is $55 \%$ mean is $49 \%$; upper $95 \%$ is $63 \%)$.

Major change $-10 \%$ of the time in bold; minor change $>5-<10$ of the time in italic. 
Table 3. Vegetation classes and significantly associated variables not used in the classification $(P<0.0001$ ANOVA). Results here are based on means comparison in the t-test and rounded to 2 decimal places. Highest that are not significantly different from each other (bold); Lowest that are not significantly different from each other (italics).

\begin{tabular}{|c|c|c|c|c|c|c|c|}
\hline Class & Class description & $\begin{array}{l}\text { Soil water } \\
(\mathrm{g} / \mathrm{g})\end{array}$ & $\begin{array}{c}\text { Soil } \\
\text { salinity } \\
\text { (ppt) }\end{array}$ & $\begin{array}{l}\text { Water table } \\
\text { salinity (ppt) }\end{array}$ & $\begin{array}{l}\text { Pneumat } \\
\text { ophores } \\
\text { (n) }\end{array}$ & $\begin{array}{l}\text { Crab holes } \\
\text { (n) }\end{array}$ & $\begin{array}{l}\text { Distance } \\
\text { from tidal } \\
\text { inlet (m) }\end{array}$ \\
\hline 1 & Extremely tall, very dense Sporobolus & 0.61 & 34.77 & 30.52 & 0.00 & 0.30 & 91.33 \\
\hline 2 & Very tall, medium dense Sporobolus & 0.61 & 36.35 & 29.62 & 0.03 & 0.23 & 90.80 \\
\hline 3 & $\begin{array}{l}\text { Very tall, medium dense Sporobolus; } \\
\text { medium, sparse Sarcocornia }\end{array}$ & 0.59 & 39.69 & 28.33 & 0.00 & 0.04 & 74.65 \\
\hline 4 & $\begin{array}{l}\text { Tall, medium dense Sporobolus; short, } \\
\text { medium dense Sarcocornia }\end{array}$ & 0.58 & 42.50 & 34.00 & 0.00 & 0.00 & 88.98 \\
\hline 5 & $\begin{array}{l}\text { Tall, sparse Sporobolus; very large, } \\
\text { dense Sarcocornia }\end{array}$ & 0.58 & 38.92 & 33.65 & 0.00 & 0.06 & 89.09 \\
\hline 6 & $\begin{array}{l}\text { Tall, sparse Sporobolus; short, } \\
\text { medium dense Sarcocornia }\end{array}$ & 0.59 & 33.65 & 27.22 & 0.09 & 0.07 & 93.03 \\
\hline 7 & Tall, very sparse Sporobolus & 0.61 & 31.92 & 28.38 & 0.01 & 0.55 & 92.45 \\
\hline 8 & $\begin{array}{l}\text { Short, very sparse Sporobolus; } \\
\text { medium, dense Sarcocornia }\end{array}$ & 0.54 & 49.45 & 35.79 & 0.08 & 0.10 & 75.81 \\
\hline 9 & $\begin{array}{l}\text { Medium, very sparse Sporobolus; } \\
\text { short, medium dense Sarcocornia }\end{array}$ & 0.58 & 39.29 & 30.52 & 0.04 & 0.15 & 88.95 \\
\hline 10 & Medium, very sparse Sporobolus & 0.61 & 33.21 & 31.22 & 0.03 & 0.84 & 84.75 \\
\hline 11 & Large, very dense Sarcocornia & 0.56 & 37.23 & 29.21 & 0.06 & 0.19 & 91.94 \\
\hline 12 & Short, medium dense Sarcocornia & 0.57 & 38.39 & 31.48 & 0.23 & 0.17 & 92.09 \\
\hline 13 & Bare mud & 0.58 & 36.10 & 29.31 & 0.44 & 1.31 & 78.02 \\
\hline
\end{tabular}


Fig. captions

Fig. 1. Classes every 3 - months from 1985 to 2005 and 2008 and for 2013.

Fig. 2. The process model.

Fig. 3. Examples of the processes for selected samples:
A. Sporobolus transitions (left side of Fig. 2);
B. Mixed spp. and Sarcocornia transitions (right side of Fig. 2) 
Fig. 1

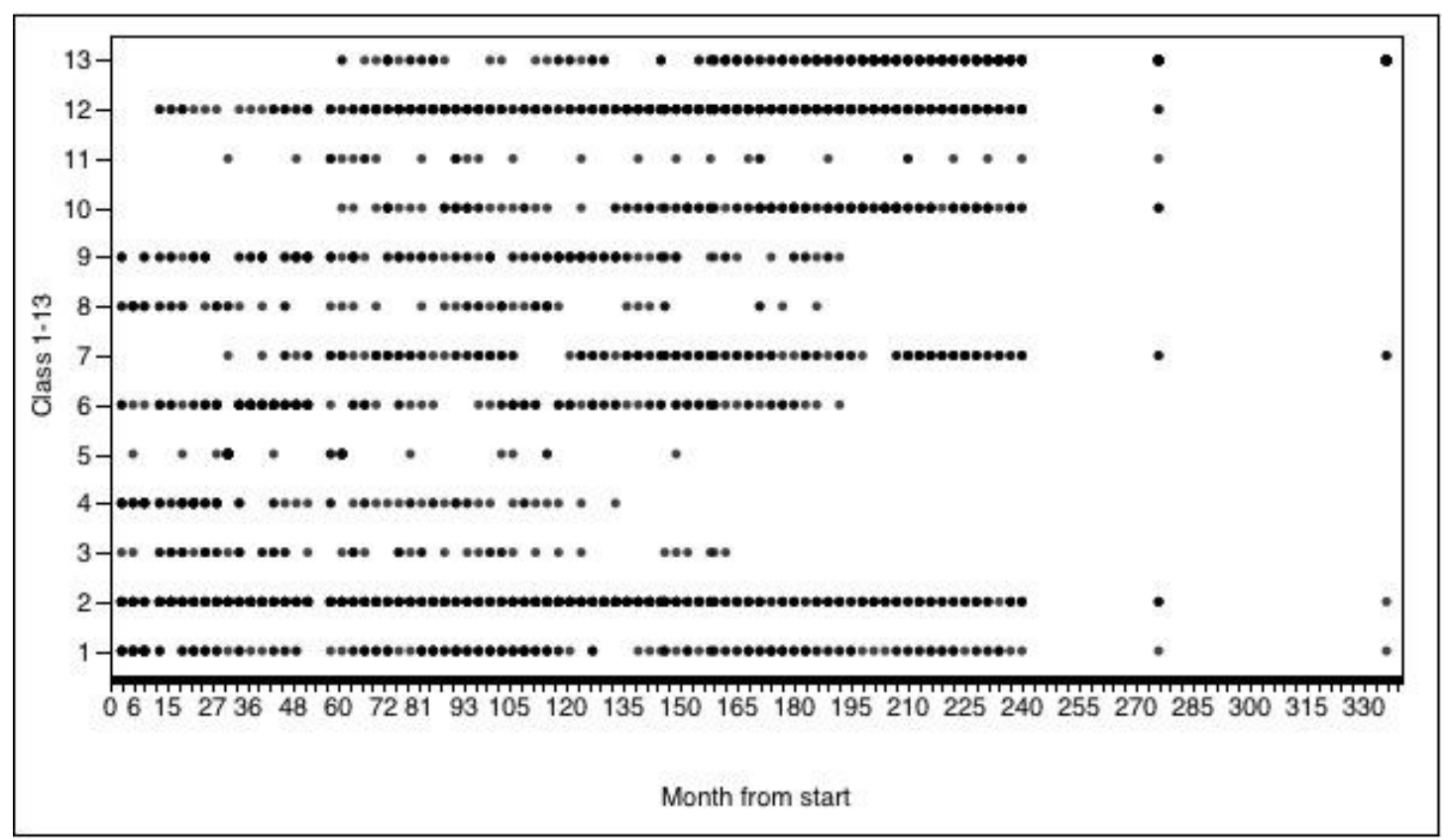

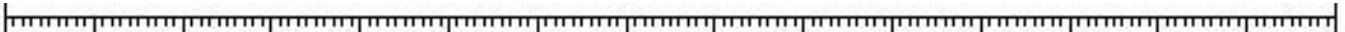
$\begin{array}{llllllllllllllll}1984 & 1986 & 1988 & 1990 & 1992 & 1994 & 1996 & 1998 & 2000 & 2002 & 2004 & 2006 & 2008 & 2010 & 2012 & 2014\end{array}$

Year 
Fig. 2

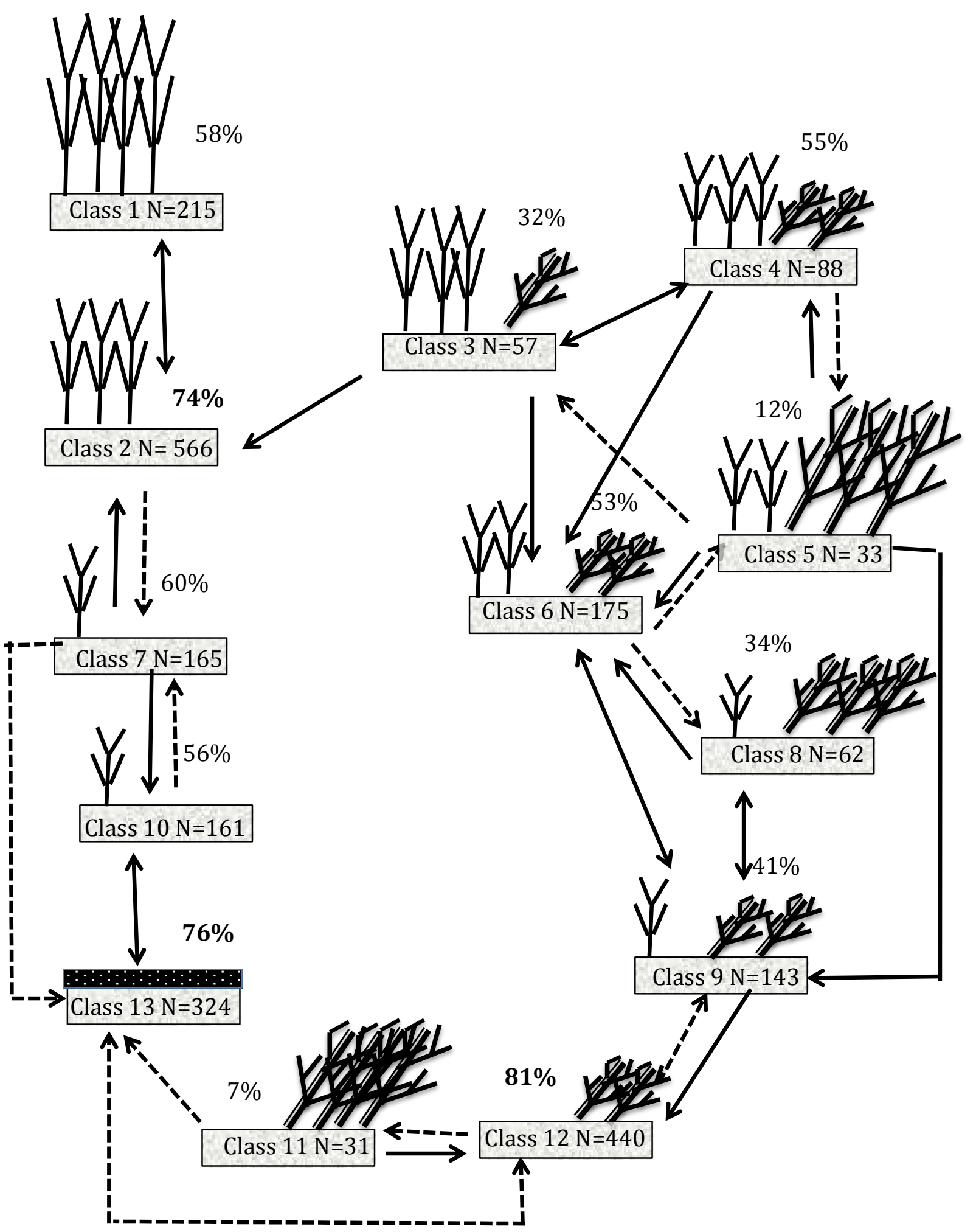


Fig. 3

Black and White A

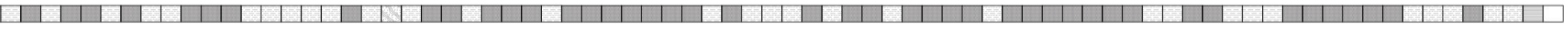

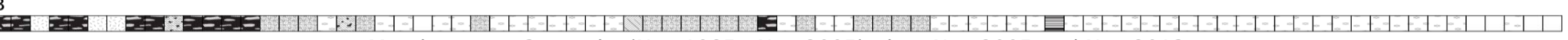
Months: every 3 months (Nov 1985 - Nov 2005), then Nov 2005 and Nov 2013

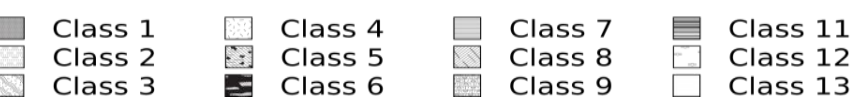

Colour 